\title{
Advanced detection and analysis of inclined shaft passing through aquifer in the mine of western China
}

\author{
Shenglin $\mathrm{Li}^{1,2}$, Liquan Guo ${ }^{1,2^{*}}$, Rongxin $\mathrm{Wu}^{1,2}$, Xiongwu $\mathrm{Hu}^{1,2}$, and Maoru $\mathrm{Fu}^{1,2}$ \\ ${ }^{1}$ State key laboratory of mining response and disaster prevention and control in deep coal mines, Huainan, Anhui, 232001, China \\ ${ }^{2}$ School of earth and environment, Anhui university of Science and technology, Huainan, Anhui, 232001, China
}

\begin{abstract}
The thick sandstone aquifer of the Cretaceous Yijun formation is rich in water and poor in predictability. Under this circumstance, the issue of the main inclined shaft of the mine in western China has been studied. Then, the comprehensive geophysical method is used in the field for advanced exploration and prediction. Based on the mine transient electromagnetic method and direct current resistivity method, the comprehensive advanced detection is carried out. Furthermore, the low resistance area in front is determined, the geological anomaly position and characteristics in front of the head are judged, and the water rich area of the detection is qualitatively evaluated, which provides support for the formulation of production technology scheme. The driving construction verification shows that the result of comprehensive geophysical exploration is basically consistent with the actual one of the shaft, and the detection accuracy of the relatively rich water area reaches over $80 \%$ which demonstrates that the comprehensive geophysical exploration method can be effectively applied into the construction of inclined shaft driving.
\end{abstract}

\section{Introduction}

During the driving of the inclined shaft of a mine, aquifer sections are often encountered. In the process of crossing the aquifer, if the detection and prediction of the aquifer cannot be carried out in advance, it is easy to cause water inrush, side slope collapse and other accidents, thus damaging the working environment and construction procedures, affecting the normal progress of the driving work, or even leading to the occurrence of major safety accidents of the shaft flooding, which pose extremely serious threats to the safe driving of the shaft. Therefore, it is very important to predict the potential water hazards in different stages of shaft construction and design scientific and reasonable production technology schemes [1].

At present, the advanced detection of shaft driving is mainly drilling. However, given the obvious limitations of drilling, the geophysical method is needed as auxiliary detection for the target area [2]. Many researchers have studied the use of geophysical methods for advanced detection of water-bearing bodies during the driving of inclined shafts. Among them, Wu et al. used the transient electromagnetic method to track and detect the grouting treatment effect of the gushing syncline structure exposed during the driving of the auxiliary inclined shaft of a mine [3]. Meng et al. used the surface direct current detection method to detect the thickness and water bearing characteristics of inclined shaft passing through the quicksand layer in advance, thus avoiding the occurrence of safety accidents [4]. All of these studies have justified the effectiveness of geophysical methods in tracking detection of water bearing body in the process of inclined shaft driving. However, due to the relativity of concept identification and the approximation of different models in the process of calculation and interpretation of geophysical data, the problems of cognitive diversity and multi solution of geophysical methods appear. As far as the single geophysical method is concerned, there are still some limitations. Therefore, it is necessary to conduct a comprehensive analysis of multiple parameters to improve the accuracy of geophysical methods [5]. A large number of researches have given affirmation to the effectiveness of comprehensive geophysical exploration technology applied in mines. For instance, Yang et al. used the controllable source audio frequency magnetotelluric method and the electromagnetic wave method to comprehensively detect the water abundance of the subsided column in the mining area, achieved good results [6]; Lu et al. used seismic reflection wave method and transient electromagnetic method to comprehensively detect water-bearing faults ahead of driving [7].

Generally mine transient electromagnetic method and direct current resistivity method are regarded as the main technical methods for advanced detection of geological problems such as mine structural water bearing property and abnormal rich water area. Despite their defects, the comprehensive application of the two methods is expected to play a more important role and achieve better results [8 10]. In this paper, the main inclined shaft of a mine in western China will pass through the thick sandy gravel stratum of the Cretaceous Yijun

* Corresponding author: 18855480918@163.com 
formation. According to the borehole inspection data, the aquifer of the formation is thick, with high confined water head and great water yield. During the construction of the shaft in the aquifer of the Yijun formation, once water is discharged head, it will have a greater impact on the freezing of the auxiliary shaft and the wind shaft and hence cause serious safety accidents. In order to identify the characteristics of the water content of the conglomerate interval and avoid the occurrence of safety accidents, it is necessary to carry out advanced detection and prediction. Therefore, based on the research background that the inclined shaft of the mine will pass through the thick sandstone aquifer of the Cretaceous Yijun formation in the process of driving, the comprehensive geophysical exploration technology combined with transient electromagnetic method and direct current resistivity method is used for tracking and detection. This paper explores the effective advanced detection method of inclined shaft passing through aquifer section in western mines of China and provides support for the formulation of production technical scheme.

\section{Aquifer characteristics and explora- tion basis of Yijun formation}

The thickness of Yijun formation aquifer is relatively stable in the study area, with a thickness of $80 \mathrm{~m} \sim 300 \mathrm{~m}$. In the area, the terrain distribution of the strata is relatively gentle, and the fluctuation is subtle. The formation is a thick-layer coarse conglomerate with a gravel diameter of $5-15 \mathrm{~cm}$. The whole gravel layer is loose, easy to expand and argillaceous when exposed to water. The aquifer is mainly recharged by the lateral runoff of regional groundwater, which is pore-fissure water. There are obviously some differences in water yield among different layers.

Studies reveal that there is a certain correlation between formation resistivity and water abundance. Coal seam, sandstone or rock mass with poor water yield usually show relatively high resistivity value, while water rich areas such as fracture development and fault zone show relatively low resistivity value. Therefore, in the process of the shaft driving through the Yijun formation aquifer, the presence of aquifer ahead of the driving will lead to abnormal reduction of formation resistivity. In this case, DC resistivity method and transient electromagnetic method can be used to detect and predict the development of water rich area in front of the driving shaft in the process of passing through the aquifer.

\section{Comprehensive Geophysical Methods}

\subsection{Principle of advanced detection technology of mine DC resistivity method}

The advanced detection technology of mine DC resistivity method is mainly based on the measurement principle of monopole-dipole resistivity method. In a homogeneous medium, a single-point power supply $A$ is used, and the other power supply electrode $B$ is placed at "infinity", so that the $B$-point power supply field can be ignored in the detection area. Among them, the equipotential surface formed by the point power supply $A$ is a spherical surface, which is used to observe the potential difference between the measuring electrodes $M$ and $N$. It is a comprehensive electrical response of the rock mass in the spherical shell clamped by $M N$ (as shown in figure 1). Calculate the apparent resistivity value according to equation (1):

$$
\rho_{s}=\frac{2 \pi \cdot|A M| \cdot|A N|}{|M N|} \frac{\Delta U_{M N}}{I}
$$

where $\rho_{s}$ is the apparent resistivity, $\Omega \cdot m ; \Delta U_{M N}$ is the potential difference between the measuring electrodes $M$ and ${ }^{N}, V$; $I$ is the supply current, $A$.

\subsection{Principle of mine transient electromagnetic advanced detection technology}

Transient electromagnetic method is used for detection by arranging coils (transmitting coil and receiving coil) in the inclined shaft head (as shown in figure 2). A current pulse square wave is supplied on the transmitting coil, and a primary magnetic field propagating to the normal direction of the transmitting coil is generated when the square wave moves forward. Under the excitation of the primary magnetic field, the geological body will produce eddy current. Upon the stop of the primary field, the eddy current will not disappear immediately until passing a transition (attenuation) process. In this process, a secondary magnetic field with attenuation is generated to propagate to the shaft head. While the coil receives the secondary magnetic field, the corresponding changes will reflect the electrical distribution of the geological body. If the secondary induced electromotive force ${ }^{V_{(t)}}$ is measured according to different delay time, the characteristic curve of secondary magnetic field attenuation with time can be obtained.

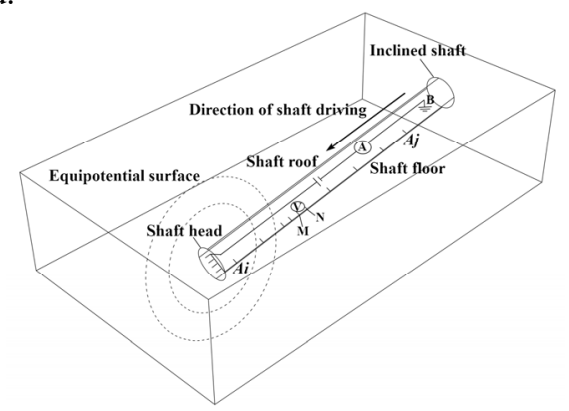

Fig. 1. Schematic diagram of advanced detection system layout of inclined shaft multi-pole power supply electric method.

According to the adopted multi-turn small coil device, the late apparent resistivity calculation equation is usually used to calculate the apparent resistivity:

$$
\rho_{\tau}(\mathrm{t})=\frac{C \mu_{0}}{4 \pi \mathrm{t}}\left(\frac{2 \mu_{0}}{5 \mathrm{t} \frac{\mathrm{dB}_{\mathrm{z}}(\mathrm{t})}{\mathrm{dt}}}\right)^{2 / 3}, \frac{\mathrm{dB}_{\mathrm{z}}(\mathrm{t})}{\mathrm{dt}}=\frac{\mathrm{V} / \mathrm{I}}{\mathrm{S} N \mathrm{sn}}
$$


where $\rho_{s}$ is the apparent resistivity; $t$ is the observation time of the secondary field attenuation, s; $\mu_{0}$ is the magnetic permeability in vacuum; $S$ is the single-turn transmit loop area, $\mathrm{m} 2 ; s$ is the single-turn receiving loop area, $\mathrm{m} 2 ; N$ and ${ }^{n}$ are the turns of the transmitting and receiving coils respectively; $V$ and $I$ are induced electromotive force (V) and current (A) respectively, $V / I$ is the received normalized secondary induced electric field value; $C$ is the approximate coefficient, which is determined by the whole space of the well, the characteristics of the coil and the electrical properties of the surrounding rock.

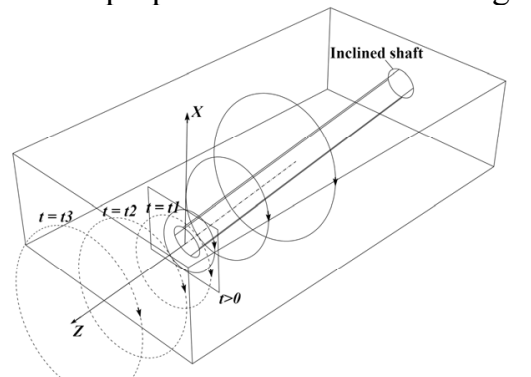

Fig. 2. Schematic diagram of current diffusion of transient electromagnetic field in inclined shaft.

The eddy current generated by electromagnetic field in the medium with strong conductivity is strong; on the contrary, it produces weak electromagnetic secondary field signals. It is precisely by taking advantage of the characteristics of transient electromagnetic field that the mine transient electromagnetic method achieves better detection effect in the current mine detection.

\section{Field Detection and Effect Analysis}

\subsection{Data acquisition and analysis of detection effect}

The layout of DC resistivity method with advanced detection and observation system is based on the actual shaft driving conditions. In the survey line layout, the appropriate position behind the shaft head determined according to the site conditions is taken as the No.1 electrode point, and the average electrode distance is $5 \mathrm{~m}$ to the head rear. A total of 32 electrodes are arranged, and the total length of the survey line is $155 \mathrm{~m}$. According to the U-shaped observation system, the advanced detection of transient electromagnetic method has been arranged and there are 11 measuring points in the shaft head. With the head center as the origin, TEM data acquisition is carried out along the $45^{\circ}$ range of the left side, head side and right side of the shaft. Three directions are observed at each data point, which are $45^{\circ}$ roof, bedding and $45^{\circ}$ floor.

Both DC resistivity method and transient electromagnetic method are highly sensitive to electrical anomalies. On this basis, the relatively low resistivity areas in the detection results can be calibrated, and these low resistivity abnormal areas can be recognized as water rich areas.
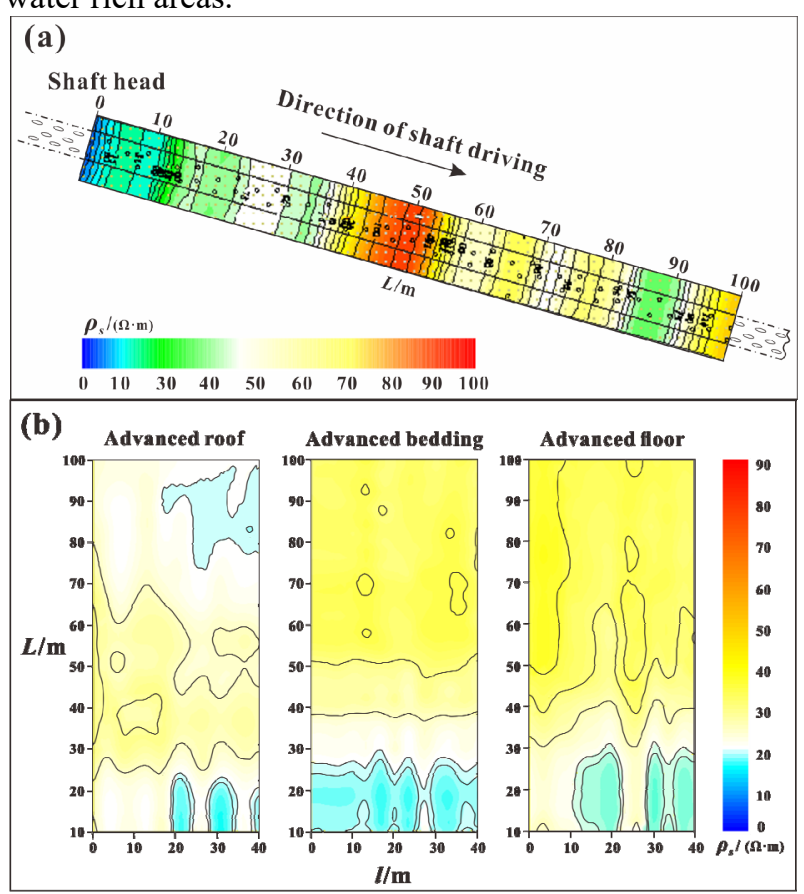

Fig. 3. Results of advanced detection by comprehensive geophysical exploration.

Figure 3 (a) shows that the resistivity in the range of $0 \sim 35 \mathrm{~m}, 70 \sim 76 \mathrm{~m}$ and $84 \sim 92 \mathrm{~m}$ within $100 \mathrm{~m}$ ahead of the detection is relatively low, which indicates that the rock stratum may have certain water bearing property or the lithology has changed to some extent. In addition, the resistivity is high in the range of $44 \sim 54 \mathrm{~m}$, which indicates that there may be no water bearing structural anomaly or the water bearing capacity of other ranges is poor. According to figure 3 (b), the apparent resistivity value within $10 \sim 30 \mathrm{~m}$ ahead of the detection is relatively low, which indicates that the rock stratum has certain water bearing capacity or the lithology of roadway rock stratum has changed; however, the water yield of rock stratum within $30 \sim 70 \mathrm{~m}$ is relatively poor.

Combined with the advanced detection results of comprehensive geophysical exploration and the geological conditions of the shaft, it is considered that within the range of $100 \mathrm{~m}$ under effective control, the strata in the $0 \sim 35 \mathrm{~m}, 70 \sim 76 \mathrm{~m}, 84 \sim 92 \mathrm{~m}$ sections in front of the exploration has certain water bearing capacity or lithology changes while the electric parameters within $44 \sim 54 \mathrm{~m}$ range change greatly, which may determine the existence of structural anomalies.

\subsection{Comprehensive detection result analysis}

After the completion of the shaft driving, the characteristics of the exposed water in the Yijun formation stratum during the construction process are summarized. It is many places are found to be characterized by water drenching and local fissure water outflow. The water output record results are shown in table 1 . 
Table 1. Investigation on water yield of main drenching section in Yijun formation.

\begin{tabular}{|c|c|c|c|c|c|c|c|}
\hline $\begin{array}{c}\text { Position of } \\
\text { water } \\
\text { drenching } \\
\text { section (m) }\end{array}$ & $657 \sim$ & $625 \sim$ & $663 \sim$ & $673 \sim$ & $758 \sim$ & 783 & $\begin{array}{c}\text { Total } \\
\text { water } \\
\text { inflow }\end{array}$ \\
\hline $\mathrm{Q} /\left(\mathrm{m}^{3} \cdot \mathrm{h}^{-1}\right)$ & 8 & 3 & 1.5 & 3.5 & 8.5 & 4.5 & 29 \\
\hline
\end{tabular}

After comparing the abnormal area delineated by the comprehensive geophysical exploration method with the actual exposure results of the shaft, it is discovered that water drenching or structural anomalies have basically occurred in the abnormal area delineated during the actual driving process (as shown in figure 4). To be specific, the four faults exposed in the inclined shaft are generally controlled within the abnormal range, and the obvious water outlet point of the main inclined shaft in the glutenite section of Yijun formation is generally controlled in the abnormal area delineated by comprehensive geophysical exploration. In general, the results of comprehensive geophysical exploration are consistent with the actual results of the shaft, and the detection accuracy of relatively rich water area is more than $80 \%$.

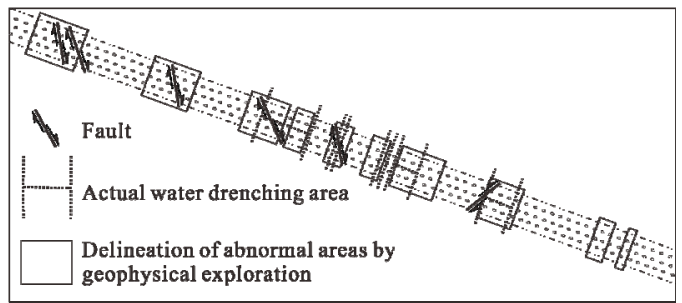

Fig. 4. Schematic diagram of comparison between comprehensive geophysical exploration delineation results and actual shaft exposure results.

\section{Conclusions}

By means of the comprehensive geophysical exploration method mine DC resistivity method and transient electromagnetic method, the low resistance area in front of inclined shaft driving as well as the geological anomaly position and characteristics in front of the head are determined. Also, the water rich area in the detection area is qualitatively evaluated. The results of comprehensive geophysical exploration are generally consistent with the actual exposure results of shaft, and the detection accuracy of relatively rich water area is more than $80 \%$, which provides support for the formulation of production technology scheme.

In summary, the comprehensive geophysical exploration method can be effectively applied into the driving construction of thick sandstone section in inclined shaft. This study can provide references for similar engineering and technical problems.

\section{Acknowledgments}

This work was supported by the National Key R\&D Program of China (No. 2016YFC0600900) and the
National Key R\&D Program of China (No. 2018YFC0807804-3).

\section{References}

1. X.H. Li, Y.N. Liu, Y.X. Pang. Application of TEM 3-D display technology in advanced detection in vertical shaft. China coal, 39(2):33-36 (2013)

2. X.D. Zhang, J.J. Zhang. Techniques applied to water-inrush control and side-wall restoration in deep vertical shaft. Journal of china coal society, 38(12): 2189-2195 (2013)

3. H.L. Wu, Z.W. Qian, B.M. Ma. Cause Analysis and Control of Water Inrush When Mine Inclined Shaft Passed Through Syncline Structure. Coal Science and Technology, 39(8): 26-29 (2011)

4. Q.B. Meng, L.J. Han, R.J. Shi, et al. Study and application of construction technology for inclined shafts penetrating drift sand strata in coal mine. Chinese Journal of Geotechnical Engineering, 37(5): 900-910 (2015)

5. S.L. Li, P.S. Zhang, H. Gui, et al. Detection of injected quality of high-iron karst roadbed by comprehensive geophysical exploration. Progress in Geophysics, 33(6): 2541-2545 (2018)

6. W.Y. Yang. Integrated geophysical prospecting principle and method of explorating the water enrichment of coal mine collapse column. Journal of Mining \& Safety Engineering, 30(1): 45-50 (2013)

7. T. Lu, S.D. Liu, B. Wang. Application of integrated mining geophysical method in detection of waterbearing faults. Progress in Geophysics, 30(3):13711375 (2015)

8. T.B. Li, L.B. Meng, J. Zhu, et al. Comprehensive analysis method for advanced forecast of geology in tunnels. Chinese Journal of Rock Mechanics and Engineering, 28(12): 2429-2436 (2009)

9. X.W. Hu, D.D. Meng, P.S. Zhang, et al. An alldirectional detection method of apparent resistivity for water from the floor strata of coal-mining face. Journal of china coal society, 44(8): 2369-2376 (2019)

10. P.S. Zhang, X.W. Hu. Research status on technology of advanced detection by electromagnetic methods in mine laneway. Coal Science and Technology, 43(1): 112-115 (2015) 